\title{
Prevalence and patterns of antifolate and chloroquine drug resistance markers in Plasmodium vivax across Pakistan
}

\author{
Aamer A Khattak', Meera Venkatesan²,3, Lubna Khatoon ', Amed Ouattara ${ }^{2}$, Leo J Kenefic ${ }^{2,4}$,
} Muhammad F Nadeem ${ }^{5,6}$, Farida Nighat ${ }^{7}$, Salman A Malik ${ }^{1}$ and Christopher V Plowe $2,3^{*}$

\begin{abstract}
Background: Plasmodium vivax is the most prevalent malaria species in Pakistan, with a distribution that coincides with Plasmodium falciparum in many parts of the country. Both species are likely exposed to drug pressure from a number of anti-malarials including chloroquine, sulphadoxine-pyrimethamine (SP), and artemisinin combination therapy, yet little is known regarding the effects of drug pressure on parasite genes associated with drug resistance. The aims of this study were to determine the prevalence of polymorphisms in the SP resistance-associated genes pvdhfr, pvdhps and chloroquine resistance-associated gene pvmdr1 in P. vivax isolates collected from across the country.
\end{abstract}

Methods: In 2011, 801 microscopically confirmed malaria-parasite positive filter paper blood samples were collected at 14 sites representing four provinces and the capital city of Islamabad. Species-specific polymerase chain reaction (PCR) was used to identify human Plasmodium species infection. PCR-positive $P$. vivax isolates were subjected to sequencing of pvdhfr, pvdhps and pvmdr1 and to real-time PCR analysis to assess pvmdr1 copy number variation.

Results: Of the 801 samples, 536 were determined to be $P$. vivax, 128 were P. falciparum, 43 were mixed vivax/ falciparum infections and 94 were PCR-negative for Plasmodium infection. Of PCR-positive P. vivax samples, 372 were selected for sequence analysis. Seventy-six of the isolates (23\%) were double mutant at positions S58R and S117N in pvdhfr. Additionally, two mutations at positions N5Ol and S93H were observed in 55 (15\%) and 24 (7\%) of samples, respectively. Three 18 base pair insertion-deletions (indels) were observed in pvdhfr, with two insertions at different nucleotide positions in 36 isolates and deletions in 10. Ninety-two percent of samples contained the pvdhps (S382/A383G/K512/A553N585) SAKAV wild type haplotype. For pvmdr1, all isolates were wild type at position Y976F and 335 (98\%) carried the mutation at codon F1076L. All isolates harboured single copies of the pvmdr1 gene.

Conclusions: The prevalence of mutations associated with SP resistance in P. vivax is low in Pakistan. The high prevalence of $P$. vivax mutant pvmdr1 codon F1076L indicates that efficacy of chloroquine plus primaquine could be in danger of being compromised, but further studies are required to assess the clinical relevance of this observation. These findings will serve as a baseline for further monitoring of drug-resistant $P$. vivax malaria in Pakistan.

Keywords: Plasmodium vivax, Malaria, Pakistan, Drug resistance, Sulphadoxine-pyrimethamine, Chloroquine, Pvmdr1, Pvdhfr, Pvdhps

\footnotetext{
* Correspondence: cplowe@medicine.umaryland.edu

${ }^{2}$ Howard Hughes Medical Institute/Center for Vaccine Development,

University of Maryland School of Medicine, Baltimore, MD, USA

${ }^{3}$ Worldwide Antimalarial Resistance Network Molecular Module, University of

Maryland School of Medicine, Baltimore, MD, USA

Full list of author information is available at the end of the article
} 


\section{Background}

Malaria imposes a significant public health burden in Pakistan, causing a reported 1.6 million cases per year according to the World Health Organization (WHO) [1]. Plasmodium vivax is the most prevalent species of human malaria in the country, accounting for 200,000 (67\%) of all cases in 2011 [2], with Plasmodium falciparum malaria accounting for the remaining one-third. Chloroquine plus primaquine is the first-line treatment for $P$. vivax in most of the world, including Pakistan. After the rise of chloroquine resistance in $P$. falciparum, sulphadoxine-pyrimethamine (SP) treatment became widespread throughout Asia and has since been replaced by artesunate plus SP for treatment of falciparum malaria in Pakistan. Despite its prevalence and public health importance, $P$. vivax has not been wellcharacterized with respect to drug resistance to chloroquine or to SP (to which it may be exposed during presumptive treatment of P. falciparum) in Pakistan [3].

Chloroquine resistance in $P$. vivax has been observed in the Pacific [4], Latin America [5], and parts of Asia $[6,7]$ but has not yet been reported in Pakistan and Afghanistan [8,9], and chloroquine remains effective against $P$. vivax in India $[10,11]$. Chloroquine resistance in $P$. vivax is thought to be mediated by single nucleotide polymorphisms (SNPs) in the pvmdr1 gene of $P$. vivax [12-14]. It has been suggested that point mutations at codons Y976F and F1076L of the pvmdr1 gene may be involved in resistance to 4-aminoquinolones, chloroquine and amodiaquine $[12,15]$. In vitro data show that Indonesian $P$. vivax isolates with a prevalence of $96 \%$ for mutation $\mathrm{Y} 976 \mathrm{~F}$ had a significantly higher $\mathrm{IC}_{50}$ for chloroquine compared to Thai isolates, which had a $25 \%$ prevalence of Y976F [16]. Whereas an association of mutation F1076L with chloroquine resistance has not yet been found $[16,17]$, the most common pvmdr1 haplotypes found in nature are F1076L [18-20], and Y976F plus F1076L [21], with the single mutantY976F reported only rarely [16]. This observation has given rise to the theory that a two-step mutational trajectory, with mutations at codon F1076L followed by Y976F, may lead to chloroquine resistance [12,22]; however, in vivo substantiation of this theory is required. Polymorphisms in copy number of the pvmdr1 gene may also modulate drug resistance in $P$. vivax, as shown by a link between gene amplification and decreased in vitro susceptibility to mefloquine, artesunate, and amodiaquine but increased susceptibility to chloroquine [23].

Although SP has not been indicated for treatment of $P$. vivax, there is evidence that intensive SP use for treatment of $P$. falciparum may also select for resistant $P$. vivax in regions where both species coexist [24-26]. An efficacy study of SP, chlorproguanil-dapsone and chloroquine carried out from 2004 to 2006 suggests that antifolates were effective against $P$. vivax in Afghanistan and Pakistan at that time [9]. In the absence of more recent data, molecular markers may be used to monitor the effects of SP pressure on P. vivax.

Pyrimethamine and sulphadoxine target the $d h f r$ and dhps enzymes in P. falciparum and point mutations in these genes confer resistance to each drug [27-34]. Mutations in codons I13L, P33L, F57L/I, S58R, T61M, S117N/T and I173L/F of the P. vivax $d h f r$ enzyme have been proposed as conferring similar resistance to pyrimethamine in P. vivax $[19,35]$. In vitro studies of $p v d h f r$ expression in Escherichia coli, $P$. falciparum and yeast have shown that $p v d h f r$ double and triple mutants S58R + S117N, F57L + S58R, and F57L + S58R + S117T confer significant (up to several hundred-fold) reductions in susceptibility to antifolates [36-39] and are associated with reduced drug affinity to the target enzyme [38]. In P. vivax dhps, mutations at codons S382A/C, A383G, K512M/T/E, and A553G/C are hypothesized to confer resistance to sulphadoxine $[25,40]$.

In Pakistan, published data are not available on the prevalence of point mutations in pvmdr1, and limited information is available regarding the prevalence of mutations in pvdhfr and pvdhps. In 2009, a study conducted in Bannu district of Pakistan reported a prevalence of $1.7 \%$ of pvdhfr F57L, 19\% for S58R and 93.5\% for S117N [3]. In pvdhps, a study conducted in 2010 in the Federally Administered Tribal Areas of Khyber Pakhtunkhwa province reported that $15 \%$ of samples had A383G and $54 \%$ had A553G/C [41]. Because up to date information on clinical efficacy and molecular markers of antimalarial resistance in Pakistan is not available, this study was designed to evaluate the current prevalence of point mutations in $p v d h f r, p v d h p s$ and $p v m d r 1$ genes of $P$. vivax in 14 sites around the country. The results presented here provide indications of whether efficacy of current anti-malarials is being maintained against $P$. vivax in Pakistan or requires further assessment.

\section{Methods}

\section{Sample collection and ethics}

Twenty-five government and private hospitals in the four provinces with the highest malaria burden (Khyber Pakhtunkhwa, Sindh, Balochistan and Punjab) along with the capital city were invited to provide samples collected during routine malaria surveillance. Fourteen facilities responded and were included in this study: Islamabad (the capital), Peshawar, Thall, Bannu and Hangu (Khyber Pakhtunkhwa Province; KPK), Karachi and Hyderabad (Sindh Province), Zhob and Quetta (Balochistan Province), Rawalpindi, Bhakhar, Mainwali, Lahore and Muzaffarghar (Punjab Province) (Figure 1) [42]. Despite the high prevalence of malaria, the Federally Administered Tribal Areas were excluded from this study because political uncertainty and terrorism [43] 


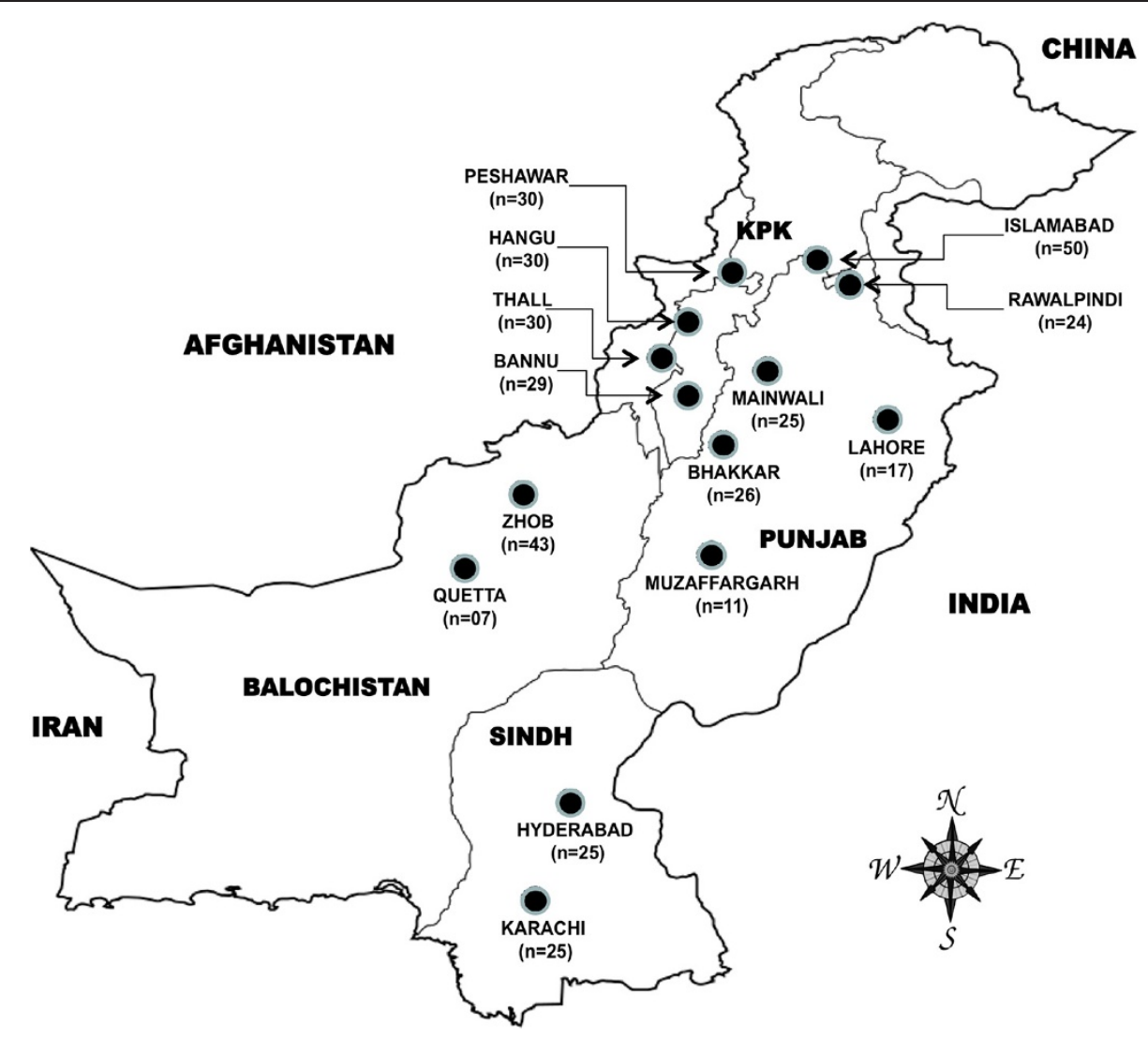

Figure 1 Plasmodium vivax collection sites and sample sizes selected for sequencing. Total sample sizes by province were as follows: Khyber Pakhtunkhwa (119), Islamabad (50), Punjab (103), Balochistan (50) and Sindh (50).

make it difficult to establish sample collection. Samples were collected between April and October 2011. A total of 10,782 symptomatic patients of all ages presenting with signs of malaria was screened for malaria infection by microscopic examination of blood by a trained laboratory technician. Approximately $3 \mathrm{ml}$ of venous blood was drawn in EDTA tubes from each patient for suspected cases after obtaining informed consent. Information on patient age, gender, and city of residence was collected. The study was approved by the institutional review board of Quaid-i-Azam University, Islamabad, Pakistan.

\section{Microscopy and dried blood spot collection}

Thick and thin blood films of patients with suspected malaria were stained with $10 \%$ Giemsa solution and slides were examined at 100X under oil immersion of microscope by laboratory technician/technologist trained in malaria diagnosis in line with WHO guidelines [44]. For samples testing positive for malaria by microscopy, $50 \mu \mathrm{l}$ blood was applied to Whatman 3MM filter paper. Blood from 30 malaria-negative samples by microscopy was also spotted on filter paper. The remaining blood from all samples was stored on site at $-80^{\circ} \mathrm{C}$. Filter papers were air-dried overnight and stored in individual plastic bags with desiccant at room temperature.

\section{DNA extraction and speciation}

DNA was isolated from 801 malaria-positive by microscopy and 30 malaria-negative filter paper samples using the QIAmp 96 DNA kit (Qiagen, Valencia, CA, USA). Isolated DNA was stored at $-20^{\circ} \mathrm{C}$ for further analysis. Plasmodium species ( $P$. vivax, $P$. falciparum, $P$. ovale and $P$. malariae) were confirmed by nested polymerase chain reaction (PCR) amplification of the small subunit ribosomal ribonucleic acid (ssrRNA) genes using primers and thermal cycler conditions as previously described [45]. Twenty-seven of the 30 microscopy-negative samples were also subjected to PCR for quality control. PCR products were visualized by $2-2.5 \%$ agarose gel electrophoresis using the Bio-Rad gel doc system (Bio-Rad, Hercules, CA, USA). Molecular analysis was conducted at the University of Maryland School of Medicine, Baltimore, USA.

\section{Amplification of $p v d h f r, p v d h p s$ and pvmdr1}

Out of 579 PCR-confirmed (536 P. vivax and $43 \mathrm{P}$. vivax/P. falciparum mixed infection) samples, 372 
isolates were randomly selected for further molecular characterization (Table 1). Target sequences of the pvdhfr, pvdhps and pvmdr1 genes harbouring known or putative mutations associated with SP and chloroquine resistance were selected for nested PCR amplification and sequencing. Primers, reagent concentrations and thermal cycling conditions were adapted from those previously published [19] with the following modifications. Denaturation was done at $94^{\circ} \mathrm{C}$ for $30 \mathrm{sec}, 2 \mu \mathrm{l}$ of DNA template was added to a total reaction volume of $50 \mu \mathrm{l}$, and the second round of PCR was carried out for a total of 25 cycles. PCR products were visualized as previously described. The expected band sizes for $p v d h f r, p v d h p s$ and pvmdr1 were 632, 767 and 547 bp, respectively.

Table 1 Prevalence of multilocus genotypes and single nucleotide polymorphism in pvdhfr, pvdhps and pvmdr1 gene of $P$. vivax

\begin{tabular}{|c|c|c|c|}
\hline Gene & Sample size & Haplotypes* & $\begin{array}{c}\text { No of isolates } \\
(\%)\end{array}$ \\
\hline \multirow[t]{6}{*}{ pvdhfr } & 336 & IPFSTSI (wild type) & $151(45)$ \\
\hline & & IPFSTN| & $100(30)$ \\
\hline & & |PFRTN| & $76(23)$ \\
\hline & & IPLRTS| & $5(1.5)$ \\
\hline & & IPFRTSI & $3(1.0)$ \\
\hline & & IPFITN| & $1(0.3)$ \\
\hline \multirow[t]{4}{*}{ pvdhps } & 339 & SAKAV (wild type) & $330(97)$ \\
\hline & & SGKAV & $7(2.0)$ \\
\hline & & SAKGV & $1(0.3)$ \\
\hline & & SGKGV & $1(0.3)$ \\
\hline \multirow[t]{10}{*}{$\begin{array}{l}\text { pvdhfr + } \\
\text { pvdhps }\end{array}$} & 322 & $\begin{array}{l}\text { IPFSTSISAKAV (wild } \\
\text { type) }\end{array}$ & $143(44)$ \\
\hline & & IPFSTNISAKAV & $95(30)$ \\
\hline & & IPFRTNISAKAV & $69(21)$ \\
\hline & & IPLRTSISAKAV & $5(1.6)$ \\
\hline & & IPFRTSISAKAV & $3(1.0)$ \\
\hline & & IPFSTNISGKAV & $2(0.6)$ \\
\hline & & IPFRTNISGKAV & $2(0.6)$ \\
\hline & & IPFSTSISAKGV & $1(0.3)$ \\
\hline & & IPFSTSISGKAV & $1(0.3)$ \\
\hline & & IPFRTNISGKGV & $1(0.3)$ \\
\hline \multirow[t]{4}{*}{ pvmdr1 } & 342 & $\begin{array}{l}\text { YF (wild type } \\
\text { genotype) }\end{array}$ & $7(2.0)$ \\
\hline & & $\begin{array}{l}\text { YL (single mutant } \\
\text { genotype) }\end{array}$ & $335(98)$ \\
\hline & & $\begin{array}{l}\text { FF (single mutant } \\
\text { genotype) }\end{array}$ & 0 \\
\hline & & $\begin{array}{l}\text { FL (double mutant } \\
\text { genotype) }\end{array}$ & 0 \\
\hline
\end{tabular}

*Drug resistance conferring point mutations are shown for the following codons: pvdhfr 13, 33, 57, 58, 61, 117, 173; pvdhps 382, 383, 512, 553, 585; and pvmdr1 976, 1076. Mutated amino acids are shown in bold.

\section{Sequencing}

Amplified secondary PCR products of $p v d h f r, p v d h p s$ and pvmdr1 genes were purified using Millipore ${ }^{\bullet}$ filtration plates (EMD Millipore, Billerica, MA, USA). The sequencing reaction for all three genes was performed in the forward and reverse directions using secondary PCR primers. The BigDye terminator v3.1 kit (ABI) was used for each sequencing reaction in the following ratios: BigDye $1 \mu \mathrm{l}$, buffers $1 \mu \mathrm{l}, 2 \mu \mathrm{mol}$ of nested PCR forward or reverse primers, purified PCR products $2 \mu \mathrm{l}$ and ultra pure water $5 \mu \mathrm{l}$ in a volume of $10 \mu \mathrm{l}$. The thermal cycler was programmed as follows: $94^{\circ} \mathrm{C}$ for $20 \mathrm{~min}, 25$ cycles of $94^{\circ} \mathrm{C}$ for $20 \mathrm{sec}, 50^{\circ} \mathrm{C}$ for $5 \mathrm{sec}, 48^{\circ} \mathrm{C}$ for $5 \mathrm{sec}, 60^{\circ} \mathrm{C}$ for $3 \mathrm{~min}$, and final extension at $60^{\circ} \mathrm{C}$ for $5 \mathrm{~min}$. Sequencing was performed using an ABI 3730XL automatic sequencer (Applied Biosystems, Foster City, CA) and sequence analyses and alignment was performed using Sequencher 4.10.1 software (Gene Codes Corp., Ann Arbor, MI, USA). Sequences of a $P$. vivax ARI/ Pakistan isolate (Gen-Bank accession no. X98123), Brazilian clinical isolate (accession no AY186730) and Sal-1 (Gen-Bank accession no. AY618622) were used as references for polymorphisms in pvdhfr, pvdhps and $p v m d r 1$.

\section{Confirmation of rare variants}

Rare or novel SNP variants were ruled out as PCR or sequencing errors as follows. SNPs occurring in a single sample and those not previously reported were reamplified by PCR and sequenced a second time to confirm presence of the polymorphism. Original and re-sequencing reactions were both conducted in the forward and reverse directions ( $2 \mathrm{X}$ coverage) to reduce the likelihood of sequencing errors.

\section{Quantification of pvmdr1 copy number}

Quantification of pvmdr1 copy number was assessed using previously described primers, probes and thermal cycler conditions [19] on a TaqMan 7700 realtime PCR machine (Applied Biosystems, Warrington, UK). Pvaldolase was used as the endogenous control and a plasmid containing a single and double copy number insert of pvmdr1 in pCR2.1 vector was used as calibrator. All samples were run in triplicate. pvmdr1 copy number values between 0.5 and 1.3 were considered as single copy, between 1.6 and 2.3 as two copies and between 2.6 and 3.3 as three copies. Assays were repeated if copy number values were between 1.3 and 1.6 and 2.3 and 2.6. Assays were also repeated if the $\mathrm{Ct}$ value exceeded 35 or the standard deviation for replicates of pvmdr1 or pvaldolase copy number exceeded 0.2. Copy number of pvmdr1 was 
estimated by using the following formula:

$$
\begin{aligned}
\Delta \Delta \mathrm{Ct}= & \left(\mathrm{Ct}_{\text {pvmdr1 }}-\mathrm{Ct}_{\text {pvaldolase }}\right) \\
& \text { sample }-\left(\mathrm{Ct}_{\text {pvmdr1 }}-\mathrm{Ct}_{\text {pvaldolase }}\right) \text { calibrator }
\end{aligned}
$$

\section{Results}

Of 801 malaria-positive isolates by microscopy, PCR analysis revealed that $536(76 \%)$ isolates were positive for P. vivax, 128 (18\%) were P. falciparum, and $43(4 \%)$ were mixed infections of both $P$. falciparum plus $P$. vivax. None of the samples was positive for $P$. malariae or P. ovale and 94 samples were PCR-negative for Plasmodium DNA. Results discordant with microscopic diagnosis were re-tested by PCR for confirmation, and a further comparison of microscopy and PCR results is presented in a separate manuscript [42]. Age among the 801 subjects ranged from two months to 75 years, with a median of 24 years. $64 \%$ of samples were collected from males and $36 \%$ from females. The gender distribution was identical and age distribution nearly identical in the subset of 372 of $579 P$. vivax-positive samples by PCR that were selected for sequencing (age range $=$ two months to 70 years; median $=25$ years). Of these, sequencing was successful in 90\% (336/372) for $p v d h f r$, 91\% (339/372) for pvdhps and 92\% (342/372) for pvmdr1. A subset of 120 PCR-positive $P$. vivax isolates was randomly selected for the quantification of pvmdr1 copy number variation, and the assay was successful in $108(90 \%)$ of isolates.

Sequenced regions of each gene were monoclonal with no evidence of mixtures of SNPs among any of the samples, allowing the investigators to identify haplotypes. For codons I13L, P33L, F57L/I, S58R, T61M, S117N/T and I173L/F of $p v d h f r, 151$ (45\%) of the isolates had the wild-type haplotype IPFSTSI. One hundred isolates (30\%) had the S117N single mutation, 76 (23\%) harboured S58R plus S117N double mutants, five isolates had the F57L plus S58R double mutant and one sample had the S58I plus S117N double mutant. The two mutations responsible for conferring pyrimethamine resistance in vitro, S58R and S117N, [46], were found in 84 (25\%) and 177 (53\%) of isolates, respectively. The pvdhfr S58R plus S117N double mutant haplotype was most prevalent among isolates in Sindh (6.8\%) and Khyber Pakhtunkhwa province (6.5\%) (Table 2). Although the pvdhfr double mutant was more common in infected patients over the age of 12 years than in children aged 12 and under prevalence of $24 \%$ versus $15 \%$, the difference was not statistically significant (chi-square $=1.87$; $\mathrm{p}=0.17$ ). Similarly, the double mutant was present in $28 \%$ of infections in females and $20 \%$ of infections in males but the difference was not significant (chi-square $=2.67 ; \quad \mathrm{p}=0.10$ ). Eight additional non- synonymous SNPs were detected, corresponding to amino acids N50I, S57R, S58R, S58I, S93R, S93H, S117N and N123K. Two of these, S93R and K123N, have not been reported previously. Non-synonymous and synonymous mutations are given in tabulated form in Additional file 1.

Based on the use of $P$. vivax strain ARI/Pakistan (GenBank accession no X98123) as reference for $p v d h f r$, three indels were detected in the study, all 18 base pairs (bp) in size (Table 3). Seven isolates had an 18 bp repeat insertion between amino acid positions 91 and 92, and 21 samples had an $18 \mathrm{bp}$ repeat insertion between codons 103 and 104. Ten isolates were discovered with an 18-bp deletion between amino acids 92 and 97.

The majority of samples were wild-type for pvdhps point mutations associated with sulphadoxine resistance, with the exception of seven samples carrying the A383G mutation, one carrying the A553G mutation, and one carrying the A383G plus A553G double mutation (Table 1). Four of the samples carrying the A383G mutation were from Khyber Pakhtunkhwa while the other three were found in each of three provinces, and the A383G plus A553G double mutant was found in Punjab (Table 2). Six non-synonymous mutations were detected (Additional file 1), four of which have not been previously reported.

The three most prevalent pvdhfr plus pvdhps haplotypes across all sites were wild-type (44\%), single $p v d h f r$ mutant $\mathrm{I}_{13} \mathrm{P}_{33} \mathrm{~F}_{57} \mathrm{~S}_{58} \mathrm{~T}_{61} \mathrm{~N} \quad{ }_{117} \mathrm{I}_{173} / \quad \mathrm{S}_{382} \mathrm{~A}_{383} \mathrm{~K}_{512} \mathrm{~A}_{553} \mathrm{~V}_{585}$ (30\%) and double pvdhfr mutant $\mathrm{I}_{13} \mathrm{P}_{33} \mathrm{~F}_{57} \mathbf{R}_{58} \mathrm{~T}_{61} \mathbf{N}$ ${ }_{117} \mathrm{I}_{173} / \mathrm{S}_{382} \mathrm{~A}_{383} \mathrm{~K}_{512} \mathrm{~A}_{553} \mathrm{~V}_{585}$ (21\%).

All isolates were wild type at pvmdr1 codon Y976F while 335 (98\%) isolates carried the point mutation at codon F1076L (Table 1). One hundred and ten, or 32\% of all isolates with pvmdr1 F1076L, were found in Khyber Pakhtunkhwa and 84 (25\%) were found in Punjab province. Three other non-synonymous SNPs (Y963C, N1010S and S1071G) not previously reported and a single synonymous SNP were also found (Additional file 1). All 108 isolates tested carried a single copy of the pvmdr1 gene.

\section{Discussion}

Pakistan adopted artesunate plus SP combination therapy as a first line treatment against uncomplicated $P$. falciparum in 2008 [47]. Chloroquine is no longer indicated for treatment of $P$. falciparum but is recommended in combination with primaquine for treatment of $P$. vivax. Although the nature of anti-malarial use in Pakistan is not well-characterized, the availability of SP and other drugs as monotherapy has been documented [48] and, along with misdiagnosis of mixed infections [49] and presumptive treatment [50], likely results in $P$. vivax infections being frequently treated 
Table 2 Prevalence and distribution of pvdhfr, pvdhps and pvmdr1 alleles by province

\begin{tabular}{|c|c|c|c|c|c|c|}
\hline & \multicolumn{2}{|c|}{${ }^{*} p v d h f r$} & \multicolumn{2}{|c|}{ pvdhps } & \multicolumn{2}{|c|}{ pvmdr1 } \\
\hline & Haplotypes & No of isolates (\%) & Haplotypes & No of isolates (\%) & Haplotypes & No of isolates (\%) \\
\hline \multirow[t]{3}{*}{ Balochistan } & IPFSTSI (wild type) & $19(5.7)$ & SAKAV (wild type) & $44(13)$ & YF (wild type) & $2(0.6)$ \\
\hline & IPFSTN| & $18(5.4)$ & SGKAV & $1(0.3)$ & $Y \mathbf{L}$ & $38(11)$ \\
\hline & IPFRTN| & $6(2)$ & & & & \\
\hline Total sequenced & $43 / 50$ & & $45 / 50$ & & $40 / 50$ & \\
\hline \multirow[t]{3}{*}{ Islamabad } & IPFSTSI & $26(7.7)$ & SAKAV & $47(14)$ & YF & $3(1.0)$ \\
\hline & IPFRTN| & $14(4.2)$ & & & $Y \mathbf{L}$ & $47(14)$ \\
\hline & IPFSTN| & $10(3.0)$ & & & & \\
\hline Total sequenced & $50 / 50$ & & $47 / 50$ & & $50 / 50$ & \\
\hline \multirow[t]{5}{*}{ Khyber Pakhtunkhwa } & IPFSTSI & $37(11)$ & SAKAV & $108(32)$ & YF & $5(2.0)$ \\
\hline & IPFSTN| & $50(15)$ & SAKGV & $1(0.3)$ & $Y \mathbf{L}$ & $110(32)$ \\
\hline & IPFRTN| & $22(6.5)$ & SGKAV & $4(1.2)$ & & \\
\hline & IPFRTSI & $2(0.6)$ & & & & \\
\hline & IPLRTSI & $1(0.3)$ & & & & \\
\hline Total sequenced & $112 / 119$ & & $113 / 119$ & & $115 / 119$ & \\
\hline \multirow[t]{5}{*}{ Punjab } & IPFSTSI & $55(16)$ & SAKAV & $89(26)$ & YF & $5(2.0)$ \\
\hline & IPFRTN| & $12(3.6)$ & SGKAV & $1(0.3)$ & $Y \mathbf{L}$ & $84(25)$ \\
\hline & IPFSTN| & $12(3.6)$ & SGKGV & $1(0.3)$ & & \\
\hline & IPLRTSI & $4(1.2)$ & & & & \\
\hline & IPFRTSI & $1(0.3)$ & & & & \\
\hline Total sequenced & $84 / 103$ & & $91 / 103$ & & $89 / 103$ & \\
\hline \multirow[t]{3}{*}{ Sindh } & IPFSTSI & $14(4.2)$ & SAKAV & $42(12)$ & YF & $2(0.6)$ \\
\hline & IPFRTN| & $23(6.8)$ & SGKAV & $1(0.3)$ & $Y \mathbf{L}$ & $46(14)$ \\
\hline & IPFSTN| & $10(3.0)$ & & & & \\
\hline Total sequenced & $47 / 50$ & & $43 / 50$ & & $48 / 50$ & \\
\hline
\end{tabular}

* Drug resistance-conferring point mutations are shown for the following codons: pvdhfr 13, 33, 57, 58, 61, 117, 173; pvdhps 382, 383, 512, 553, 585; and pvmdr1 976, 1076. Mutated amino acids are shown in bold.

with AS + SP or SP alone. This study sought to characterize the current distribution of chloroquine resistance-associated polymorphisms in pvmdr1 and SP resistance-associated point mutations in $p v d h f r$ and pvdhps in Pakistan.

Resistance of $P$. falciparum to chloroquine is nearly fixed in Pakistan [3,51], and the emergence of chloroquineresistant $P$. vivax in neighbouring India [52-54] along with established resistance in Thailand [55,56], Indonesia $[57,58]$ and Vietnam [59] suggests that the treatment of $P$. vivax with chloroquine in Pakistan could be in danger of being compromised. Clinical trials conducted during 2004-2006 indicate that chloroquine was still efficacious against $P$. vivax in Pakistan [9]. As a more recent follow-on to clinical evidence, this study presents the first report of $p v m d r 1$ gene polymorphisms in Pakistan. Nearly all isolates were wild type at pvmdr1 Y796F, suggesting that chloroquine resistance in $P$. vivax has not emerged, but many carried the F1076L mutant. These results are consistent with previous studies showing the rise of $p v m d r 1$ F1076L prior to Y976F $[12,23,60]$. If the hypothesis that the two-step trajectory of mutations at codon F1076L followed by Y976F may lead to chloroquine resistance [12] is correct, then pvmdr1 F1076L may provide an early signal of emerging chloroquine resistance in Pakistan prior to the appearance of the drug resistance phenotype in the population [22], particularly in

Table 3 Insertions and deletions in pvdhfr gene of Plasmodium vivax

\begin{tabular}{cccc}
\hline Insertions/Deletions & Codons & No of bp & Sequence \\
\hline Insertion A & 91,92 & $18 \mathrm{bp}$ samples \\
Insertion B & 103,104 & $18 \mathrm{bp}$ & ACACACGGTGGTGACAAC \\
Deletion & 92,97 & $18 \mathrm{bp}$ & ACACACGGTGGTGACAAT \\
\hline
\end{tabular}


Khyber Pakhtunkhwa where its prevalence is highest. Polymorphisms in pvmdr1 should continue to be monitored in case the mutation at position Y976F appears. Amplification of the pvmdrl gene was not detected in this study, reflecting the absence of mefloquine drug pressure in Pakistan. Regions with a history of mefloquine use for falciparum malaria have shown amplification of both pfmdr1 in $P$. falciparum and pvmdr1 in $P$. vivax, likely caused by inadvertent drug exposure $[17,23]$.

Plasmodium vivax is likely exposed to SP pressure (either alone or in combination with artesunate) in a bystander effect, particularly because it is found alongside $P$. falciparum in regions with mixed-species infections such as Balochistan (10\%), Khyber Pakhtunkhwa (8\%), and Punjab (5\%) [42], that are vulnerable to misdiagnosis of Plasmodium species [3,41,49,51]. Exposure of $P$. vivax parasites to SP pressure, with likely subtherapeutic levels in some patients, could favour the emergence of SP resistance [61].

In this study, the pvdhfr double mutant S58R and S117N was found in $20 \%$ of isolates. The double mutant has been reported previously from one site in Pakistan [3] as well as in neighbouring India [62] and Iran [63], and is associated with in vitro pyrimethamine resistance [64]. In contrast, point mutations in pvdhps A383G and A553G were detected in a very small number of samples, confirming similar results from a previous report in Bannu district in 2007 [3]. These mutations have also been reported as rare in Iran [63] and Afghanistan [65], suggesting that markers associated with sulphadoxine resistance in $P$. vivax remain rare in this region. Because SP treatment failure is closely associated with infections carrying four or more mutations in pvdhfr [35] and additional pvdhps mutations [66], it appears that SP likely remains efficacious against $P$. vivax in Pakistan as previously reported [9].

The prevalence of pvdhfr S117N single and S58R plus S117N double mutants was highest in Sindh and Khyber Pakhtunkhwa provinces. Khyber Pakhtunkhwa had the second highest prevalence of mixed species and $P$. falciparum infections in this survey [42], indicating that perhaps regions with $P$. falciparum experience higher SP use (with or without artesunate) that also exerts pressure on cooccurring $P$. vivax infections. Khyber Pakhtunkhwa province also had the highest prevalence of pvmdr1 F1076L mutants, and may be especially vulnerable to the influx or emergence of drug-resistant parasites because of the largescale migration of Afghan refugees and internally displaced people (IDPs) from conflict areas to this region, along with conditions of underdevelopment that may prevent adequate diagnosis and treatment of malaria [67].

\section{Conclusions}

This is the first comprehensive report on molecular patterns of drug resistance in P. vivax in Pakistan. The major chloroquine resistance-mediating mutation was not detected in this study; however continued molecular monitoring of polymorphisms in pvmdr1 is crucial to detect the potential emergence of chloroquine-resistant $P$. vivax in Pakistan. Although some evidence of pyrimethamine selective pressure was observed, polymorphisms associated with sulphadoxine resistance were rare, and markers of clinically relevant SP resistance in $P$. vivax were not present. Thus, the data on molecular markers presented here suggest that efficacy of both chloroquine and SP against $P$. vivax is currently high, and can serve as a baseline reference for regional studies of $P$. vivax drug sensitivity in Pakistan.

\section{Additional file}

Additional file 1: Synonymous and non-synonymous SNPs detected in pvdhfr, pvdhps and pvmdr1.

\section{Competing interests}

The authors declare that they have no competing interests.

\section{Authors' contributions}

AAK designed study, carried out the laboratory experiments, and performed data analysis. AAK and MV drafted the manuscript. AO and LJK contributed to laboratory experiments and sequence analysis. MFN and FN participated in sample collection and microscopy. MV, LK, SAM and CVP provided guidance and coordination for study design, genotyping, and data analyses, and edited and revised the manuscript. All authors read and approved the final manuscript.

\section{Acknowledgements}

The authors also thank Matthew Adams, Malathi Vadla and Sudhaunshu Joshi at the University of Maryland for their technical assistance and Muhammad Shahid, Ismail Jalil, Ifthikhar Ahmed, Adeel Riaz, Muhammad Adnan, Ihsan Khan and Noor Rehman in Pakistan for help with sample collection. This work was supported by a grant from the Higher Education Commission of Pakistan in support of AAK's PhD studies at Quaid-i-Azam University, Islamabad, Pakistan, and was supported in part by the Howard Hughes Medical Institute at the University of Maryland School of Medicine, Baltimore, MD, USA

\section{Author details}

${ }^{1}$ Department of Biochemistry, Faculty of Biological Sciences, Quaid-i-Azam University, Islamabad, Pakistan. ${ }^{2}$ Howard Hughes Medical Institute/Center for Vaccine Development, University of Maryland School of Medicine, Baltimore, MD, USA. ${ }^{3}$ Worldwide Antimalarial Resistance Network Molecular Module, University of Maryland School of Medicine, Baltimore, MD, USA. ${ }^{4}$ Department of Medical and Research Technology, University of Maryland School of Medicine, Baltimore, MD, USA. ${ }^{5}$ King Edward Medical University, Lahore, Pakistan. ${ }^{6}$ Department of Biochemistry and Molecular Biology, University of Gujrat, Gujrat, Pakistan. 'Islamic International Medical College, Rawalpindi, Pakistan.

Received: 30 May 2013 Accepted: 29 August 2013

Published: 5 September 2013

\section{References}

1. WHO: World malaria report 2012. Geneva: World Health Organization; 2013.

2. D MC: Malaria No More. Islamabad: Directorate of Malaria Control, Ministry of National Health Services; 2013.

3. Khatoon L, Baliraine FN, Bonizzoni M, Malik SA, Yan G: Prevalence of antimalarial drug resistance mutations in Plasmodium vivax and $P$. falciparum from a malaria-endemic area of Pakistan. Am J Trop Med Hyg 2009, 81:525-528. 
4. Rieckmann $\mathrm{KH}$, Davis DR, Hutton DC: Plasmodium vivax resistance to chloroquine? Lancet 1989, 2:1183-1184

5. Soto J, Toledo J, Gutierrez P, Luzz M, Llinas N, Cedeno N, Dunne M, Berman $\mathrm{J}$ : Plasmodium vivax clinically resistant to chloroquine in Colombia. Am J Trop Med Hyg 2001, 65:90-93.

6. Kurcer MA, Simsek Z, Kurcer Z: The decreasing efficacy of chloroquine in the treatment of Plasmodium vivax malaria, in Sanliurfa, south-eastern Turkey. Ann Trop Med Parasitol 2006, 100:109-113.

7. Phan GT, de Vries PJ, Tran BQ, Le HQ, Nguyen NV, Nguyen TV, Heisterkamp SH, Kager PA: Artemisinin or chloroquine for blood stage Plasmodium vivax malaria in Vietnam. Trop Med Int Health 2002, 7:858-864.

8. Awab GR, Pukrittayakamee S, Imwong M, Dondorp AM, Woodrow CJ, Lee SJ, Day NP, Singhasivanon P, White NJ, Kaker F: Dihydroartemisininpiperaquine versus chloroquine to treat vivax malaria in Afghanistan: an open randomized, non-inferiority, trial. Malar J 2010, 9:105.

9. Leslie T, Mayan MI, Hasan MA, Safi MH, Klinkenberg E, Whitty CJ, Rowland M: Sulfadoxine-pyrimethamine, chlorproguanil-dapsone, or chloroquine for the treatment of Plasmodium vivax malaria in Afghanistan and Pakistan: a randomized controlled trial. JAMA 2007, 297:2201-2209.

10. Valecha N, Joshi H, Eapen A, Ravinderan J, Kumar A, Prajapati SK, Ringwald $P$ : Therapeutic efficacy of chloroquine in Plasmodium vivax from areas with different epidemiological patterns in India and their Pvdhfr gene mutation pattern. Trans R Soc Trop Med Hyg 2006, 100:831-837.

11. Nandy A, Addy M, Maji AK, Bandyopadhyay AK: Monitoring the chloroquine sensitivity of Plasmodium vivax from Calcutta and Orissa, India. Ann Trop Med Parasitol 2003, 97:215-220.

12. Brega S, Meslin B, de Monbrison F, Severini C, Gradoni L, Udomsangpetch R, Sutanto I, Peyron F, Picot S: Identification of the Plasmodium vivax mdr-like gene (pvmdr1) and analysis of single-nucleotide polymorphisms among isolates from different areas of endemicity. J Infect Dis 2005, 191:272-277.

13. Nomura T, Carlton JM, Baird JK, Del Portillo HA, Fryauff DJ, Rathore D, Fidock DA, Su X, Collins WE, McCutchan TF, Wootton JC, Wellems TE: Evidence for different mechanisms of chloroquine resistance in 2 Plasmodium species that cause human malaria. J Infect Dis 2001, 183:1653-1661.

14. Sa JM, Nomura T, Neves J, Baird JK, Wellems TE, Del Portillo HA: Plasmodium vivax: allele variants of the $\mathrm{mdr} 1$ gene do not associate with chloroquine resistance among isolates from Brazil, Papua, and monkeyadapted strains. Exp Parasitol 2005, 109:256-259.

15. Marfurt J, de Monbrison F, Brega S, Barbollat L, Muller I, Sie A, Goroti M, Reeder JC, Beck HP, Picot S, Genton B: Molecular markers of in vivo Plasmodium vivax resistance to amodiaquine plus sulfadoxinepyrimethamine: mutations in pvdhfr and pvmdr1. J Infect Dis 2008, 198:409-417.

16. Suwanarusk R, Russell B, Chavchich M, Chalfein F, Kenangalem E, Kosaisavee $\mathrm{V}$, Prasetyorini B, Piera KA, Barends M, Brockman A, Lek-Uthai $U$, Anstey NM, Tjitra E, Nosten F, Cheng Q, Price RN: Chloroquine resistant Plasmodium vivax: in vitro characterisation and association with molecular polymorphisms. PLoS One 2007, 2:e1089.

17. Imwong M, Pukrittayakamee S, Pongtavornpinyo W, Nakeesathit S, Nair S, Newton P, Nosten F, Anderson TJ, Dondorp A, Day NP, White NJ: Gene amplification of the multidrug resistance 1 gene of Plasmodium vivax isolates from Thailand, Laos, and Myanmar. Antimicrob Agents Chemother 2008, 52:2657-2659.

18. Lu F, Wang B, Cao J, Sattabongkot J, Zhou H, Zhu G, Kim K, Gao Q, Han ET: Prevalence of drug resistance-associated gene mutations in Plasmodium vivax in Central China. Korean J Parasitol 2012, 50:379-384.

19. Mint LK, Ould Mohamed Salem BA, Gaillard T, Wurtz N, Bogreau H, Hafid JE, Trape JF, Bouchiba H, Ould Ahmedou Salem MS, Pradines B, Rogier C, Basco LK, Briolant S: Molecular surveillance of drug-resistant Plasmodium vivax using pvdhfr, pvdhps and pvmdr1 markers in Nouakchott, Mauritania. J Antimicrob Chemother 2012, 67:367-374.

20. Ranjitkar S, Schousboe ML, Thomsen T, Adhikari M, Kapel CM, Bygbjerg IC, Alifrangis M: Prevalence of molecular markers of anti-malarial drug resistance in Plasmodium vivax and Plasmodium falciparum in two districts of Nepal. Malar J 2011, 10:75.

21. Jovel IT, Mejia RE, Banegas E, Piedade R, Alger J, Fontecha G, Ferreira PE, Veiga MI, Enamorado IG, Bjorkman A, Ursing J: Drug resistance associated genetic polymorphisms in Plasmodium falciparum and Plasmodium vivax collected in Honduras. Central America Malar J 2011, 10:376.

22. Orjuela-Sanchez $P$, Karunaweera ND, da Silva-Nunes M, da Silva NS, Scopel KK, Goncalves RM, Amaratunga C, Sa JM, Socheat D, Fairhust RM,
Gunawardena S, Thavakodirasah T, Galapaththy GL, Abeysinghe R, Kawamoto F, Wirth DF, Ferreira MU: Single-nucleotide polymorphism, linkage disequilibrium and geographic structure in the malaria parasite Plasmodium vivax: prospects for genome-wide association studies. BMC Genet 2010, 11:65

23. Suwanarusk R, Chavchich M, Russell B, Jaidee A, Chalfein F, Barends M, Prasetyorini B, Kenangalem E, Piera KA, Lek-Uthai U, Anstey NM, Tjitra E, Nosten F, Cheng Q, Price RN: Amplification of pvmdr1 associated with multidrug-resistant Plasmodium vivax. J Infect Dis 2008, 198:1558-1564.

24. Alam MT, Bora H, Bharti PK, Saifi MA, Das MK, Dev V, Kumar A, Singh N, Dash AP, Das B, Wajihullah, Sharma YD: Similar trends of pyrimethamine resistance-associated mutations in Plasmodium vivax and $P$. falciparum. Antimicrob Agents Chemother 2007, 51:857-863.

25. Hastings MD, Porter KM, Maguire JD, Susanti I, Kania W, Bangs MJ, Sibley $\mathrm{CH}$, Baird JK: Dihydrofolate reductase mutations in Plasmodium vivax from Indonesia and therapeutic response to sulfadoxine plus pyrimethamine. J Infect Dis 2004, 189:744-750.

26. Imwong M, Pukrittayakamee S, Renia L, Letourneur F, Charlieu JP, Leartsakulpanich U, Looareesuwan S, White NJ, Snounou G: Novel point mutations in the dihydrofolate reductase gene of Plasmodium vivax: evidence for sequential selection by drug pressure. Antimicrob Agents Chemother 2003, 47:1514-1521.

27. Wang P, Read M, Sims PF, Hyde JE: Sulfadoxine resistance in the human malaria parasite Plasmodium falciparum is determined by mutations in dihydropteroate synthetase and an additional factor associated with folate utilization. Mol Microbiol 1997, 23:979-986.

28. Triglia T, Cowman AF: Primary structure and expression of the dihydropteroate synthetase gene of Plasmodium falciparum. Proc Natl Acad Sci USA 1994, 91:7149-7153.

29. Triglia T, Menting JG, Wilson C, Cowman AF: Mutations in dihydropteroate synthase are responsible for sulfone and sulfonamide resistance in Plasmodium falciparum. Proc Natl Acad Sci USA 1997, 94:13944-13949.

30. Peterson DS, Walliker D, Wellems TE: Evidence that a point mutation in dihydrofolate reductase-thymidylate synthase confers resistance to pyrimethamine in falciparum malaria. Proc Natl Acad Sci USA 1988, 85:9114-9118.

31. Peterson DS, Milhous WK, Wellems TE: Molecular basis of differential resistance to cycloguanil and pyrimethamine in Plasmodium falciparum malaria. Proc Natl Acad Sci USA 1990, 87:3018-3022.

32. Foote SJ, Galatis D, Cowman AF: Amino acids in the dihydrofolate reductasethymidylate synthase gene of Plasmodium falciparum involved in cycloguanil resistance differ from those involved in pyrimethamine resistance. Proc Natl Acad Sci USA 1990, 87:3014-3017.

33. Cowman AF, Morry MJ, Biggs BA, Cross GA, Foote SJ: Amino acid changes linked to pyrimethamine resistance in the dihydrofolate reductasethymidylate synthase gene of Plasmodium falciparum. Proc Natl Acad SCi USA 1988, 85:9109-9113.

34. Brooks DR, Wang P, Read M, Watkins WM, Sims PF, Hyde JE: Sequence variation of the hydroxymethyldihydropterin pyrophosphokinase: dihydropteroate synthase gene in lines of the human malaria parasite, Plasmodium falciparum, with differing resistance to sulfadoxine. Eur J Biochem 1994, 224:397-405.

35. Hawkins VN, Joshi H, Rungsihirunrat K, Na-Bangchang K, Sibley CH: Antifolates can have a role in the treatment of Plasmodium vivax Trends Parasitol 2007, 23:213-222.

36. Auliff A, Wilson DW, Russell B, Gao Q, Chen N, Anh LN, Maguire J, Bell D, O'Neil MT, Cheng Q: Amino acid mutations in Plasmodium vivax DHFR and DHPS from several geographical regions and susceptibility to antifolate drugs. Am J Trop Med Hyg 2006, 75:617-621.

37. Hastings MD, Sibley CH: Pyrimethamine and WR99210 exert opposing selection on dihydrofolate reductase from Plasmodium vivax. Proc Natl Acad Sci USA 2002, 99:13137-13141.

38. Hastings MD, Maguire JD, Bangs MJ, Zimmerman PA, Reeder JC, Baird JK, Sibley CH: Novel Plasmodium vivax dhfr alleles from the Indonesian Archipelago and Papua New Guinea: association with pyrimethamine resistance determined by a Saccharomyces cerevisiae expression system. Antimicrob Agents Chemother 2005, 49:733-740.

39. Leartsakulpanich U, Imwong M, Pukrittayakamee S, White NJ, Snounou G, Sirawaraporn W, Yuthavong Y: Molecular characterization of dihydrofolate reductase in relation to antifolate resistance in Plasmodium vivax. Mol Biochem Parasitol 2002, 119:63-73. 
40. Triglia T, Wang P, Sims PF, Hyde JE, Cowman AF: Allelic exchange at the endogenous genomic locus in Plasmodium falciparum proves the role of dihydropteroate synthase in sulfadoxine-resistant malaria. EMBO J 1998, 17:3807-3815

41. Zakeri S, Afsharpad M, Ghasemi F, Raeisi A, Kakar Q, Atta H, Djadid ND: Plasmodium vivax: prevalence of mutations associated with sulfadoxinepyrimethamine resistance in Plasmodium vivax clinical isolates from Pakistan. Exp Parasitol 2011, 127:167-172.

42. Khattak AA, Venkatesan M, Nadeem MF, Satti HS, Yaqoob, Strauss, Khatoon, Malik S, Plowe CV: Prevalence and distribution of human Plasmodium infection in Pakistan. Malar J 2013, 12(1):297. [Epub ahead of print] PubMed PMID: 23984968.

43. Nawaz S: FATA—A Most Dangerous Place. Washington, D.C: Center for Strategic and International Studies; 2009.

44. Asif SA: Departmental audit of malaria control programme 2001-2005 north west frontier province (NWFP). J Ayub Med Coll Abbottabad 2008, 20:98-102.

45. Snounou G, Viriyakosol S, Jarra W, Thaithong S, Brown KN: Identification of the four human malaria parasite species in field samples by the polymerase chain reaction and detection of a high prevalence of mixed infections. Mol Biochem Parasitol 1993, 58:283-292.

46. Tjitra E, Baker J, Suprianto S, Cheng Q, Anstey NM: Therapeutic efficacies of artesunate-sulfadoxine-pyrimethamine and chloroquine-sulfadoxine -pyrimethamine in vivax malaria pilot studies: relationship to Plasmodium vivax dhfr mutations. Antimicrob Agents Chemother 2002, 46:3947-3953.

47. WHO: World Malaria Report 2008. Geneva: World Health Organization; 2009

48. Khan SY, Khan A, Arshad M, Tahir HM, Mukhtar MK, Ahmad KR, Arshad N: Irrational use of antimalarial drugs in rural areas of eastern Pakistan: a random field study. BMC Publ Health 2012, 12:941.

49. Zakeri S, Kakar Q, Ghasemi F, Raeisi A, Butt W, Safi N, Afsharpad M, Memon MS, Gholizadeh S, Salehi M, Atta H, Zamani G, Djadid ND: Detection of mixed Plasmodium falciparum \& $P$. vivax infections by nested-PCR in Pakistan, Iran \& Afghanistan. Indian J Med Res 2010, 132:31-35.

50. Malik M, Hassali MAA, Shafie AA, Hussain A: Why Don't Medical Practitioners Treat Malaria Rationally? A Qualitative Study from Pakistan. Trop J Pharm Res 2012, 4:673-681.

51. Ghanchi NK, Ursing J, Beg MA, Veiga MI, Jafri S, Martensson A: Prevalence of resistance associated polymorphisms in Plasmodium falciparum field isolates from southern Pakistan. Malar J 2011, 10:18.

52. Dua VK, Kar PK, Sharma VP: Chloroquine resistant Plasmodium vivax malaria in India. Trop Med Int Health 1996, 1:816-819.

53. Garg M, Gopinathan N, Bodhe P, Kshirsagar NA: Vivax malaria resistant to chloroquine: case reports from Bombay. Trans R Soc Trop Med Hyg 1995, 89:656-657.

54. Van den Abbeele K, Van den Enden E, Van den Ende J: Combined chloroquine and primaquine resistant Plasmodium vivax malaria in a patient returning from India. Ann Soc Belg Med Trop 1995, 75:73-74.

55. Congpuong K, Na-Bangchang K, Thimasarn K, Tasanor U, Wernsdorfer WH: Sensitivity of Plasmodium vivax to chloroquine in Sa Kaeo Province, Thailand. Acta Trop 2002, 83:117-121.

56. Looareesuwan S, Buchachart K, Wilairatana P, Chalermrut K, Rattanapong Y, Amradee S, Siripiphat S, Chullawichit S, Thimasan K, Ittiverakul M, Triampon A, Walsh DS: Primaquine-tolerant vivax malaria in Thailand. Ann Trop Med Parasitol 1997, 91:939-943.

57. Schwartz IK, Lackritz EM, Patchen LC: Chloroquine-resistant Plasmodium vivax from Indonesia. N Engl J Med 1991, 324:927.

58. Collignon P: Chloroquine resistance in Plasmodium vivax. J Infect Dis 1991, 164:222-223.

59. Taylor WR, Doan HN, Nguyen DT, Tran TU, Fryauff DJ, Gomez-Saladin E, Kain KC, Le DC, Baird JK: Assessing drug sensitivity of Plasmodium vivax to halofantrine or choroquine in southern, central Vietnam using an extended 28-day in vivo test and polymerase chain reaction genotyping. Am J Trop Med Hyg 2000, 62:693-697.

60. Orjuela-Sanchez P, de Santana Filho FS, Machado-Lima A, Chehuan YF, Costa MR, Alecrim M, Del Portillo HA: Analysis of single-nucleotide polymorphisms in the crt-o and mdr1 genes of Plasmodium vivax among chloroquine-resistant isolates from the Brazilian Amazon region. Antimicrob Agents Chemother 2009, 53:3561-3564.

61. Hastings $I M$, Watkins WM: Tolerance is the key to understanding antimalarial drug resistance. Trends Parasitol 2006, 22:71-77.
62. Prajapati SK, Joshi H, Dev V, Dua VK: Molecular epidemiology of Plasmodium vivax anti-folate resistance in India. Malar J 2011, 10:102.

63. Zakeri S, Motmaen SR, Afsharpad M, Djadid ND: Molecular characterization of antifolates resistance-associated genes, (dhfr and dhps) in Plasmodium vivax isolates from the Middle East. Malar J 2009, 8:20

64. Imwong M, Pukrittakayamee S, Looareesuwan S, Pasvol G, Poirreiz J, White $\mathrm{NJ}$, Snounou G: Association of genetic mutations in Plasmodium vivax dhfr with resistance to sulfadoxine-pyrimethamine: geographical and clinical correlates. Antimicrob Agents Chemother 2001, 45:3122-3127.

65. Zakeri S, Afsharpad M, Ghasemi F, Raeisi A, Safi N, Butt W, Atta H, Djadid ND: Molecular surveillance of Plasmodium vivax dhfr and dhps mutations in isolates from Afghanistan. Malar J 2010, 9:75.

66. Imwong M, Pukrittayakamee S, Cheng Q, Moore C, Looareesuwan S, Snounou G, White NJ, Day NP: Limited polymorphism in the dihydropteroate synthetase gene (dhps) of Plasmodium vivax isolates from Thailand. Antimicrob Agents Chemother 2005, 49:4393-4395.

67. Department of Health Government of Khyber Pakhtunkhwa: Brief of roll back malaria programme Khyber Pakhtunkhwa. ; 2013:1-3. http://www.healthkp. gov.pk/downloads/rbm.doc.

doi:10.1186/1475-2875-12-310

Cite this article as: Khattak et al:: Prevalence and patterns of antifolate and chloroquine drug resistance markers in Plasmodium vivax across Pakistan. Malaria Journal 2013 12:310.

\section{Submit your next manuscript to BioMed Central and take full advantage of:}

- Convenient online submission

- Thorough peer review

- No space constraints or color figure charges

- Immediate publication on acceptance

- Inclusion in PubMed, CAS, Scopus and Google Scholar

- Research which is freely available for redistribution

Submit your manuscript at www.biomedcentral.com/submit
C Biomed Central 